\title{
Impact of stroke-associated pneumonia on mortality, length of hospitalization and functional outcome
}

Wen-Hui Teh ${ }^{\text {a }}$, Craig J Smith, MD ${ }^{\text {b, }}$; Raphae S Barlas, MPH ${ }^{\text {a }}$, Adrian D Wood, $\mathrm{PhD}^{\text {a }}$; Joao H Bettencourt-Silva, $\mathrm{PhD}^{\mathrm{a}, \mathrm{e}}$; Allan B Clark, $\mathrm{PhD}^{\mathrm{d}}$; Anthony K Metcalf, MBChB ${ }^{\text {e,f. }}$; Kristian M Bowles, PhD ${ }^{\text {d,e }}$; John F Potter, MD $^{\text {d,e }}$;Phyo K Myint, MD ${ }^{\mathrm{a}, \mathrm{e}}$

anstitute of Applied Health Sciences, School of Medicine, Medical Sciences and Nutrition, University of Aberdeen, AB25 2ZD, UK

${ }^{\mathrm{b}}$ Greater Manchester Comprehensive Stroke Centre, Manchester Academic Health Science

Centre, Salford Royal NHS Foundation Trust, M6 8HD

${ }^{\mathrm{c}}$ Faculty of Biology, Medicine and Health, University of Manchester, Manchester, M13 9PL, UK

${ }^{\mathrm{d} N o r w i c h ~ M e d i c a l ~ S c h o o l, ~ U n i v e r s i t y ~ o f ~ E a s t ~ A n g l i a, ~ N o r w i c h, ~ N R 4 ~ 7 T J, ~ U K ~}$

${ }^{\text {e }}$ Stroke Research Group, Norwich Cardiovascular Research Group, Norwich Research Park, Norwich, NR4 7TJ, UK

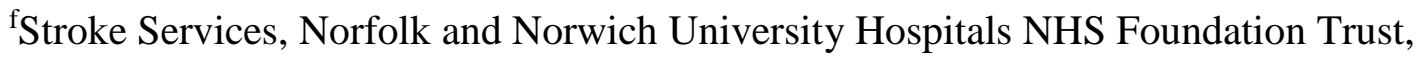

Norwich, NR4 7UY, UK

\section{Correspondence to:}

Professor Phyo Kyaw Myint

Room 4:013, Polwarth Building,

School of Medicine, Medical Sciences and Nutrition

University of Aberdeen

Foresterhill

AB25 2ZD

Aberdeen, Scotland, UK

Tel: +44 (0) 1224437974

Fax: +44(0) 1224437911

Mail to: phyo.myint@abdn.ac.uk

Word count: 3,386 
Running title: Impact of SAP on adverse outcomes after stroke

\section{$\underline{\text { Abstract }}$}

Objectives: Stroke-Associated Pneumonia (SAP) is common and associated with adverse outcomes. Data on its impact beyond one year is scarce.

Materials and methods: This observational study was conducted in a cohort of stroke patients admitted consecutively to a tertiary referral centre in the East of England, UK (January 2003 - April 2015). Logistic regression models examined in-patient mortality and length of stay (LOS). Cox-regression models examined longer term mortality at pre-defined time periods (0-90 days, 90 days-1 year, 1-3 years and 3-10 years) for SAP. Effect of SAP on functional outcome at discharge was assessed using logistic regression.

Results: A total of 9,238 patients [mean age ( \pm SD) $77.61 \pm 11.88$ years] were included. SAP was diagnosed in $1,083(11.7 \%)$ patients. The majority of these cases $(n=658 ; 60.8 \%)$ were aspiration pneumonia. After controlling for age, sex, stroke type, Oxfordshire Community Stroke Project classification (OCSP), pre-stroke modified Rankin scale, co-morbidities and acute illness markers, mortality estimates remained significant at three time periods; inpatient (OR 5.87, 95\%CI [4.97-6.93]), 0-90 days (2.17[1.97-2.40]) and 91-365 days (HR 1.31[1.031.67]). SAP was also associated with higher odds of long LOS (OR 1.93[1.67-2.22]) and worse functional outcome, (OR 7.17(5.44-9.45). In this cohort, SAP did not increase mortality risk beyond one year post stroke but it was associated with reduced mortality beyond 3 years.

Conclusions: SAP is not associated with increased long term mortality but is linked with increased mortality up to 1 year, prolonged LOS, and poor functional outcome on discharge. Targeted intervention strategies are required to improve outcomes of SAP patients who survive to hospital discharge.

Key words: Acute stroke, mortality, prognosis, stroke-associated pneumonia 


\section{Introduction}

Pneumonia associated with stroke is common and often leads to poor clinical outcomes, with a recent systematic review reporting a prevalence of $14.3 \%{ }^{1}$ The pathophysiology of stroke-associated pneumonia (SAP) is multifactorial. Specifically, a combination of dysphagia leading to oro-pharyngeal aspiration and stroke-induced immunosuppression as a result of acute cerebral ischemia have been posited as possible mechanisms. ${ }^{2}$ SAP may also consist of cases of pneumonia which precede the incident stroke thereby contributing to stroke etiopathogenesis. ${ }^{3}$

Despite advances in organized stroke unit care over the last few decades, ${ }^{4}$ SAP continues to have negative impact on outcomes. ${ }^{5-10}$ SAP is independently associated with a 3fold increase in mortality during hospital admission, ${ }^{11}$ worse functional outcomes, ${ }^{9}$ longer length of hospitalization ${ }^{5,7,10,12,13}$ and higher hospital costs. ${ }^{14}$ There is an extensive amount of research on the early outcome of SAP, however, it remains unclear whether or not the increased mortality risk persists after 1-year due to heterogeneity of these studies and lack of long-term follow up. ${ }^{2}$

It is well-recognized that acute stroke induces both central nervous system (CNS) and peripheral inflammatory responses. Indeed, peripheral inflammatory markers are persistently elevated after stroke (to at least 3 months) compared to non-stroke controls, and are exacerbated by infectious complications. ${ }^{15,16}$ Peripheral inflammatory markers in the acute phase of stroke are associated with worse functional outcome, survival and recurrent vascular events in the interim and longer term. ${ }^{17} \mathrm{SAP}$, by augmenting acute and longer term inflammatory responses, complicating stroke might therefore plausibly contribute to longer term outcome after stroke.

We hypothesized that SAP has adverse effects on longer-term outcomes compared to non-SAP. The main aim of this study therefore, was to investigate the association between 
SAP and adverse outcomes including mortality at different pre-defined time periods; short (inpatient and 90 days), medium (91 days - 1 year) and long-term (1-3 years and 3-10 years). We also aimed to evaluate the effect of SAP on length of hospital stay and functional outcome at discharge. Our secondary aim was to explore the association between different types of SAP, namely aspiration and non-aspiration pneumonia based on clinicians' diagnosis.

\section{Materials and methods}

Study participants and design

Out of 11,886 entries on the stroke register, 9,238 patients with acute stroke who were admitted between 2003-2015 were included in the study. Supplementary Figure a-1 details the reasons for exclusion. Baseline demographic and clinical data of study participants were extracted from the comprehensive stroke and TIA register of a tertiary regional stroke center and ethical approval was granted by the Newcastle and Tyneside National Health Service (NHS) Research Ethics Committee (12/NE/0170).

All acute stroke cases were verified by stroke physicians based on clinical features and CT/MRI imaging. SAP was defined as pneumonia diagnosed on admission or within the first seven days of admission after stroke onset. ${ }^{18}$ Information on the incidence of SAP (aspiration or non-aspiration) were retrieved from the hospital Patient Administration System (PAS), reviewed and identified with codes in the $10^{\text {th }}$ revision of the International Classification of Disease (ICD-10), based on previously employed methods. ${ }^{19-22}$ The diagnosis of pneumonia was made by clinicians during the hospital stay based on signs and symptoms suggestive of acute lower respiratory tract infection based on British Thoracic Society (BTS) guidelines and previous studies. ${ }^{19}$ Further classification into aspiration and non-aspiration pneumonia was made by the clinician based on distinguishing features such as dysphagia status, nil by mouth and location of shadowing on chest X-ray, however the 
accuracy may be limited by the lack of validated criteria for diagnosing aspiration pneumonia. $^{22}$ The following diagnosis codes classified as SAP in the current study- J69; aspiration pneumonia and non-aspiration pneumonia including J12; Viral pneumonia, J13; Pneumonia due to Streptococcus pneumoniae, J14; due to Haemophilus-influenzae, J15; Bacterial, J16; Other infectious organisms, J17; pneumonia in diseases classified elsewhere and J18; unspecified organisms.

\section{Study outcomes}

The outcomes of interest were 1) Mortality - short term mortality (in-patient and 90 days), medium (91 days - 1 year) and long term mortality (1-3 years and 3-10 years poststroke); 2) Long length of stay (LOS), defined as >14 days; 3) Functional outcome depicted by the modified Rankin Scale (mRS) score at discharge. The outcome was dichotomized as good (0-2) and poor (3-6). ${ }^{23}$ Linkage with the Office of National Statistics (ONS) for mortality data ensures near complete follow-up for this outcome.

\section{Potentially confounding covariates}

Data were collected on pre-existing co-morbidities. This information was retrieved from the hospital's administration database. Co-morbid conditions examined in this study were stroke [ICDI60-64], transient ischaemic attack (TIA) [G45], coronary heart disease (CHD) [I20-25], myocardial infarction (MI) [I21], atrial fibrillation (AF) [I48], congestive heart failure (CHF) [I50], hypertension [I10-15], dyslipidaemia [E78], diabetes mellitus [E10-14], peripheral vascular disease (PVD) [I73.9], chronic obstructive pulmonary disease (COPD) [J40-44,J47], asthma [J45], previous pneumonia [J69, J12-18], chronic kidney disease (CKD) [N18], malignancy [C00-97], and dementia [F00-05]). Biochemical and 
haematological measurements relevant to acute inflammatory response including total white cell count (WCC) and C-Reactive Protein (CRP) were collected on hospital admission.

\section{Statistical Analysis}

All analyses were agreed a-priori to avoid biased post-hoc decisions. We employed SPSS for Windows version 23.0 (SPSS Inc., Chicago, IL, USA). Chi-squared tests for categorical variables and Mann-Whitney $U$ tests for continuous variables were used to compare the characteristics of those with and without SAP. Logistic regression models were constructed to examine in-patient mortality following SAP while Cox-regression models were used to examine longer term mortality outcomes (0-90 days, 91 days-1 year, 1-3 years and 3-10 years). Separate analyses were performed for each follow up period with subsequent models excluding patients for whom follow-up ended during the preceding period. This approach allowed us to consider the changing risk profile with older age after stroke. Analyses were conducted as follows: unadjusted (model A) and using five risk adjustment models that successively added covariates to control for age and sex (model B), stroke subtype (ischemic vs. hemorrhagic), OCSP classification, prior antiplatelet use (model C), co-morbidities (model D) and pre-stroke modified Rankin score (model E). Model F additionally controlled for WCC and CRP in a subgroup of patients where these parameters were available $(n=7,425)$. Other stroke outcomes (long length of hospital stay and functional outcome) were assessed using binary logistic regression.

The models were repeated to compare the outcomes in between aspiration (ICD J69) vs. non-aspiration pneumonia (ICD J12 - 18) based on their respective ICD codes using nonaspiration pneumonia as the reference category and the fully-adjusted regression model as described. To investigate for any change in trend for mortality over the study period of 4263 
days, survival following diagnosis of stroke according to pneumonia status and type of SAP were plotted and illustrated by the Kaplan-Meier survival curves.

\section{Results}

The prevalence of SAP was $11.7 \%(n=1,083)$. The mean age (SD) was $77.61 \pm 11.88$ years, with $47.5 \%$ males, and $87.0 \%$ having had ischemic stroke. $77.1 \%$ cases of pneumonia were diagnosed on the same day as hospital admission and crude inpatient mortality was $21.3 \%$ in those with SAP. Table 1 illustrates the baseline characteristics by pneumonia status and type. Those with SAP were older, more likely to have a diagnosis of total anterior circulation stroke (TACS) and had a higher pre-stroke mRS. A significantly higher proportion of SAP patients had cardiovascular risk factors (hypertension and diabetes mellitus) and other co-morbid cardio-pulmonary conditions, dementia and malignancy.

History of previous episode of pneumonia was significantly higher in patients who had SAP compared to those without SAP $(15.1 \%$ vs $4.6 \%$; $<0.001)$. In patients with SAP, $60.8 \%$ were diagnosed with aspiration pneumonia. The age, severity of stroke depicted by OCSP and pre-stroke frailty depicted by pre-stroke mRS did not affect the prevalence of one type of pneumonia over the other. Patients with non-aspiration pneumonia were more likely to have COPD, CKD and higher median CRP [Median (IQR) 32(65.0) vs 23 (55.0)] mg/L on admission.

Table 2 shows the mortality outcome during different time periods. The highest mortality following stroke was observed between 0 - 90 days while the risk of mortality was at its lowest after 3 years. The cumulative mortality was significantly greater for patients with SAP, particularly in those diagnosed with aspiration pneumonia. Supplementary Figure a-2 and a-3 show KM cumulative survival by pneumonia status and type for the overall stroke cohort. The curve plateaus after approximately 1 year for those with SAP, indicating that the 
excess/increased risk of mortality persists for 1 year in patients with SAP, after which SAP patients have a similar, then lower mortality rate to those without pneumonia beyond 3 years. Supplementary Figure a-4 shows that SAP conferred higher odds of inpatient and 0-90 days mortality in patients diagnosed with aspiration pneumonia (OR 1.54 and HR 1.29, respectively) compared to those diagnosed with non-aspiration pneumonia $(\mathrm{p}<0.005)$. They were also more likely to be associated with worse functional outcome (95.7\% vs $88.7 \%$, $\mathrm{p}<0.001)$ but the length of hospitalization was not significantly different. A log rank test for equality of survival functions showed a large difference between the different groups over 10 years of follow up $(\mathrm{p}<0.001)$.

Table 3 depicts the risk of mortality of SAP at various time intervals and the odds of prolonged LOS (>14 days) using non-pneumonia patients as reference. Patients with SAP had higher mortality rate compared with those without SAP at three time periods assessed (in-patient, 0-90 days and 91-365 days). SAP was associated with 5.87 times increased odds of in-patient mortality (95\%CI 4.97 to 6.93 ), two times increased risk of 0-90 days mortality (HR 2.17 [95\%CI 1.97 to 2.40]) and 31\% increase in relative risk up to one year (95\% CI: $3 \%-67 \%)$. The risk of mortality remained consistently high up to 1 year despite further adjustments for WCC and CRP. However, it was noted that relative risk of mortality for SAP was halved (HR 0.50, 95\%CI: 0.32-0.78) in those who survived beyond 3 years. We found a two-fold increase in the odds of long length of hospital stay in patients with SAP.

The functional outcomes at discharge were available for 6,013 (65.1\%) patients. Of those, 2,286 (38\%) had good outcome (mRS 0-2) and 3,727 (62\%) had poor outcome (mRS 3-6). Patients with SAP had significantly worse functional outcomes at discharge (OR 7.17 [95\%CI 5.44-9.45]). Poor outcomes were observed in 885 (93\%) of those with SAP ( $n=952)$ compared with 2,842 (56.2\%) of those without $(n=5,061)$ (Supplementary Figure a-5). 


\section{Discussion}

Our results confirm that SAP adversely affects mortality up to 1 year and is associated with prolonged hospitalization and poor functional status at discharge in patients after stroke, even after adjustment for various established prognostic factors. We further established that patients diagnosed with aspiration pneumonia have a higher short term mortality compared to patients diagnosed with non-aspiration pneumonia.

SAP is arguably a preventable complication, which warrants increased efforts to identify those at risk and develop interventions to reduce incident cases given the impact of pneumonia on poor outcomes. To our knowledge, this is the first study analyzing the effect of SAP on mortality risk up to ten years of follow up. Existing literature either did not examine the mortality in specified time period or only took into account outcomes that developed early within 7 days to 3 months after stroke. ${ }^{7,9}$ Our long-term follow-up using consecutively admitted patient information enables us to provide novel insights into the longer-term prognosis of SAP.

The overall frequency of SAP was $11.7 \%$, corroborating results observed in previous studies. ${ }^{9,21,24}$ Patients with SAP were older, more likely to have a diagnosis of TACS, had a higher pre-stroke mRS and had more additional co-morbidities, and higher inflammatory markers. These findings, in line with previous studies, ${ }^{5,11,12}$ suggest that patients with SAP have a higher severity of disease, medical complexity and frailty. We found that $77.1 \%$ of patients with SAP were diagnosed on the day of admission. This figure is higher than that reported in the literatures, i.e 40-68\%.6,21,25 This discrepancy may be explained by marked heterogeneity between studies, influenced by factors such as study population, environment and approach to diagnosis. ${ }^{1}$ Our higher rate of pickup may also be due to the presence of a hyperacute bay with constant physiological monitoring which may benefit from more rigorous detection of infection. However, the early diagnosis of SAP in our study did not 
translate into better outcomes which may be explained by the lack of efficacy of prophylactic antibiotics given within 24 and 48 hours of stroke onset as shown in two recent trials. ${ }^{26,27}$ It has been proposed that administration of preventative antibiotics in these trials may in fact have been too late to prevent SAP and that the results are limited by the heterogeneity of antibiotics choice. ${ }^{28}$ This necessitates a paradigm shift to initiate preventative interventions, for those at risk of SAP, in the hyperacute phase (under 24 hours) of stroke in future large clinical trials.

There is substantial variation in terms of the reported mortality rate across different studies. $5,6,8,12,13,29$ The overall mortality rates in this study were slightly higher than previous studies, with $61.5 \%$ at discharge and $73.6 \%$ at 1 year (Table 2). Notably, we observed excess mortality from SAP even among those surviving up to one year following hospitalization. This was accompanied by a plateau and reduction in mortality risk after 3 years. Although this observation has not been previously described, several mechanisms have been proposed to explain this effect. This finding could be influenced by the small number of patients with SAP who survived beyond 3 years. Alternatively, we may be limited by residual confounding. Despite robust covariate adjustments in our study, it is possible that better prognosis after three years in participants with SAP could be attributable to other factors that were not accounted for in our analyses, such as newly developing chronic co-morbid disease impacting on mortality. Whilst the overall sample size is reasonable between $3-10$ years $(n=5,223)$, only 208 patients with SAP have survived up to 3 years suggesting that most who will die as a result of SAP would have died within the first 3 years after stroke. This may also be because of the significantly higher age of patients with SAP, resulting in earlier death (before 3 years) due to age-related factors compared to patients without SAP. Furthermore, it is also possible that the severity of SAP they had was mild leading to lower risk in later time periods. It is probable that non-SAP group is catching up with mortality as those who survived beyond 
three years have higher co-morbid burden with time and associated increased frailty which were not accounted for in the analysis.

One study used survival analyses to examine the long term impact of the medical complications in stroke patients beyond 1 year. ${ }^{24}$ It was shown that cumulative mortality continued to rise over the entire follow up period (4 years), never reaching a plateau. The authors highlighted that the excess risk of death following medical complication never abated, suggesting that the characteristics of the population were responsible rather than the insults of the complication episode. The findings of the present study are an initial observation and whether this represents the true impact of SAP on long term outcomes needs to be further tested in different populations.

Traditionally, SAP has been thought to be aspiration related secondary to dysphagia. However, recent studies have shown that up to half of patients that develop pneumonia post stroke do not aspirate which implies that not all SAP is aspiration-related. ${ }^{6}$ In line with published literature, ${ }^{20,30}$ we observed differences in the characteristics and outcomes between the diagnoses of aspiration and non-aspiration pneumonia. Those diagnosed with aspiration pneumonia were more likely to have higher short term mortality and poor functional outcome compared to those with non-aspiration pneumonia. Patients with aspiration pneumonia had a significantly higher proportion of TACS compared to non-aspiration pneumonia when tested for statistical significance individually and this may reflect higher severity of disease in those diagnosed with aspiration pneumonia. We controlled for stroke type, stroke severity and a wide range of confounding factors in our multivariable analyses. Therefore, outcomes are likely due to the type of pneumonia. Although we acknowledge that we were limited by the lack of dysphagia status in patients. For stroke patients truly experiencing aspiration, the pathophysiological basis for poorer outcomes can be explained by the presence of oropharyngeal or gastric contents in the airway which can result in a higher severity of 
epithelial disruption, impaired gas exchange and prolonged healing than when the airway is exposed to exogenous bacteria alone. ${ }^{31,32}$

However, the accuracy of categorizing aspiration and non-aspiration pneumonia by hospital clinicians is not within the scope of this study and the retrospective nature of this study does not allow verification of the accuracy of the type of pneumonia diagnosis. The difficulties in studying aspiration pneumonia is well recognized throughout the literature due to the lack of a sensitive and specific marker for aspiration pneumonia, as well as the potential overlap of clinical signs and symptoms between aspiration pneumonia and other forms of pneumonia. ${ }^{33}$ Although we categorized SAP into aspiration vs non-aspiration subtypes based on available clinical and investigation data for the analyses, we acknowledge that accurately discriminating these subtypes in clinical practice is challenging and the prognostic value is uncertain.

Our study has several strengths. The nature of our study with a long follow-up period enabled us to provide more robust prognostic information on the long-term impact of SAP. This study is also unique in having a large and well-defined stroke population that is representative of real-world stroke population, all of whom had relevant measurements of disease at baseline and were followed prospectively until death or the end of study period. The availability of these information allowed us to adjust for many potential confounders in our analysis including inflammatory markers which are important determinants of stroke outcome. $^{15}$

Our study has several limitations in addition to those described earlier. The clinical severity of pneumonia was not accounted for in this study and misclassification of pneumonia type is a possibility due to lack of a "gold standard" for the diagnosis of aspiration pneumonia. We had to rely on the clinician's best judgment to determine if the mechanism of pneumonia was aspiration or non-aspiration and this carries a margin of error. ${ }^{34}$ However, the 
data came from a single unit with yearly patient flow of approximately 1,000 per annum stroke cases looked after by a single stroke team with 3-5 consultants during the study period. The shift system within the NHS suggests that most patients were looked after by more than one consultant in each hospital episode and hence any disagreement in diagnosis would have been resolved with final coding verified. The discharge mRS were only available in $65.1 \%$ of the population, which could have led to underestimation of the functional outcome. Nevertheless, the internal relationship between SAP and outcome is unlikely to be different. Finally, data to assess the severity of stroke impairment such as the National Institute of Health Stroke Scale (NIHSS) were not available. However, we adjusted for OCSP classification and pre-stroke mRS, which has been shown to be indicative of major determinants of mortality in stroke. ${ }^{35}$

We found that SAP was not associated with poorer long term outcomes. However, our findings that SAP is significantly associated with higher mortality up to 1 year, longer hospitalization and worse functional outcome highlight the importance of early identification and treatment of SAP. Future efforts should aim to develop better ways of identifying stroke patients at high risk for aspiration and pneumonia and on strategies to prevent this complication. 


\section{Acknowledgement}

We thank the data team of the Norfolk and Norwich University Hospital Stroke Services.

\section{Contributors}

PKM and CJS conceived the study. WHT performed literature search and analyzed the data under supervision of RSB, ADW and ABC. JHBS was responsible for data management. PKM is the principal investigator and AKM, KMB and JFP are co- principal investigator of the NNUH Stroke Register. WHT drafted the draft version of the manuscript and all authors contributed to the manuscript. PKM is the guarantor of the content of the manuscript, including the data and analysis.

Conflict of interest: None 


\section{References:}

1. Kishore AK, Vail A, Chamorro A, et al. How Is Pneumonia Diagnosed in Clinical Stroke Research? A Systematic Review and Meta-Analysis. 2015;46(5):1202-1209.

2. Hannawi Y, Hannawi B, Rao CP, Suarez JI, Bershad EM. Stroke-associated pneumonia: major advances and obstacles. Cerebrovascular diseases (Basel, Switzerland). 2013;35(5):430-443.

3. Emsley HCA, Hopkins SJ. Acute ischaemic stroke and infection: recent and emerging concepts. The Lancet Neurology. 2008;7(4):341-353.

4. Smith EE, Hassan KA, Fang J, et al. Do all ischemic stroke subtypes benefit from organized inpatient stroke care?(e-Pub ahead of print). Neurology. 2010;75(5):456462.

5. Finlayson O, Kapral M, Hall R, et al. Risk factors, inpatient care, and outcomes of pneumonia after ischemic stroke. Neurology. 2011;77(14):1338-1345.

6. Katzan IL, Cebul RD, Husak SH, Dawson NV, Baker DW. The effect of pneumonia on mortality among patients hospitalized for acute stroke. Neurology. 2003;60(4):620625.

7. Koennecke HC, Belz W, Berfelde D, et al. Factors influencing in-hospital mortality and morbidity in patients treated on a stroke unit. Neurology. 2011;77(10):965-972.

8. Ingeman A, Andersen G, Hundborg HH, Svendsen ML, Johnsen S. Processes of Care and Medical Complications in Patients With Stroke. Stroke. 2010;42(1):167.

9. Hong KS, Kang DW, Koo JS, et al. Impact of neurological and medical complications on 3-month outcomes in acute ischaemic stroke. European Journal of Neurology. 2008;15(12):1324-1331.

10. Ickenstein GW, Riecker A, Hohlig C, et al. Pneumonia and in-hospital mortality in the context of neurogenic oropharyngeal dysphagia (NOD) in stroke and a new NOD step-wise concept. Journal of neurology. 2010;257(9):1492-1499.

11. Sellars C, Bowie L, Bagg J, et al. Risk Factors for Chest Infection in Acute Stroke. $A$ Prospective Cohort Study. 2007;38(8):2284-2291.

12. Vermeij FH, Scholte op Reimer WJ, de Man P, et al. Stroke-associated infection is an independent risk factor for poor outcome after acute ischemic stroke: data from the Netherlands Stroke Survey. Cerebrovascular diseases (Basel, Switzerland). 2009;27(5):465-471.

13. Aslanyan $\mathrm{S}$, Weir $\mathrm{CJ}$, Diener $\mathrm{HC}$, et al. Pneumonia and urinary tract infection after acute ischaemic stroke: a tertiary analysis of the GAIN International trial. European journal of neurology. 2004;11(1):49-53.

14. Wilson RD. Mortality and Cost of Pneumonia After Stroke for Different Risk Groups. Journal of Stroke and Cerebrovascular Diseases. 2010;21(1):61-67.

15. Emsley HC, Smith CJ, Gavin CM, et al. An early and sustained peripheral inflammatory response in acute ischaemic stroke: relationships with infection and atherosclerosis. J Neuroimmunol. 2003;139(1-2):93-101.

16. Ladenvall C, Jood K, Blomstrand C, Nilsson S, Jern C, Ladenvall P. Serum C-reactive protein concentration and genotype in relation to ischemic stroke subtype. Stroke. 2006;37(8):2018-2023. 
17. Smith CJ, Lawrence CB, Rodriguez-Grande B, Kovacs KJ, Pradillo JM, Denes A. The immune system in stroke: clinical challenges and their translation to experimental research. J Neuroimmune Pharmacol. 2013;8(4):867-887.

18. Smith CJ, Kishore AK, Vail A, et al. Diagnosis of Stroke-Associated Pneumonia. Stroke. 2015;46(8):2335.

19. Lim WS, Baudouin SV, George RC, et al. BTS guidelines for the management of community acquired pneumonia in adults: update 2009. Thorax. 2009;64 Suppl 3:iii1-55.

20. Lanspa MJ, Jones BE, Brown SM, Dean NC. Mortality, morbidity, and disease severity of patients with aspiration pneumonia. Journal of hospital medicine. 2013;8(2):83-90.

21. Davenport RJ, Dennis MS, Wellwood I, Warlow CP. Complications after acute stroke. Stroke. 1996;27(3):415-420.

22. Lanspa MJ, Peyrani P, Wiemken T, Wilson EL, Ramirez JA, Dean NC. Characteristics associated with clinician diagnosis of aspiration pneumonia: a descriptive study of afflicted patients and their outcomes. J Hosp Med. 2015;10(2):90-96.

23. van Swieten JC, Koudstaal PJ, Visser MC, Schouten HJ, van Gijn J. Interobserver agreement for the assessment of handicap in stroke patients. Stroke; a journal of cerebral circulation. 1988;19(5):604-607.

24. Bae H-J, Yoon D-S, Lee J, et al. In-Hospital Medical Complications and Long-Term Mortality After Ischemic Stroke. Stroke. 2005;36(11):2441.

25. Hassan A, Khealani BA, Shafqat S, et al. Stroke-associated pneumonia: microbiological data and outcome. Singapore Med J. 2006;47(3):204-207.

26. Westendorp WF, Vermeij JD, Zock E, et al. The Preventive Antibiotics in Stroke Study (PASS): a pragmatic randomised open-label masked endpoint clinical trial. Lancet. 2015;385(9977):1519-1526.

27. Kalra L, Irshad S, Hodsoll J, et al. Prophylactic antibiotics after acute stroke for reducing pneumonia in patients with dysphagia (STROKE-INF): a prospective, clusterrandomised, open-label, masked endpoint, controlled clinical trial. Lancet. 2015;386(10006):1835-1844.

28. Meisel A, Smith CJ. Stroke: Preventive antibiotics for stroke-associated pneumonia. Nat Rev Neurol. 2015;11(12):672-673.

29. Ifejika-Jones NL, arun N, Peng H, Elizabeth A, Grotta JC, Francisco GE. The interaction of aspiration pneumonia with demographic and cerebrovascular disease risk factors is predictive of discharge level of care in acute stroke patient. Am J Phys Med Rehabil. 2012;91(2):141-147.

30. Thomson J, Hall M, Ambroggio L, et al. Aspiration and Non-Aspiration Pneumonia in Hospitalized Children With Neurologic Impairment. Pediatrics. 2016.

31. Pawlik MT, Schreyer AG, Ittner KP, et al. Early treatment with pentoxifylline reduces lung injury induced by acid aspiration in rats. Chest. 2005;127(2):613-621.

32. Amigoni $M$, Bellani $G$, Scanziani $M$, et al. Lung injury and recovery in a murine model of unilateral acid aspiration: functional, biochemical, and morphologic characterization. Anesthesiology. 2008;108(6):1037-1046.

33. Paul EM. Aspiration Pneumonitis and Aspiration Pneumonia. The New England Journal of Medicine. 2001;344::665-671.

34. Naidech AM, Liebling SM, Duran IM, Moore MJ, Wunderink RG, Zembower TR. Reliability of the validated clinical diagnosis of pneumonia on validated outcomes after intracranial hemorrhage. J Crit Care. 2012;27(5):527 e527-511. 
35. Bamford J, Sandercock P, Dennis M, Burn J, Warlow C. Classification and natural history of clinically identifiable subtypes of cerebral infarction. Lancet (London, England). 1991;337(8756):1521-1526. 

Table 1. Characteristics of stroke patients at admission by pneumonia status and type

\begin{tabular}{|c|c|c|c|c|c|c|c|}
\hline \multirow[t]{2}{*}{ Characteristics } & \multicolumn{7}{|c|}{ Stroke-Associated Pneumonia } \\
\hline & $\begin{array}{l}\text { Total } \\
n=9238\end{array}$ & $\begin{array}{l}\text { Yes } \\
\mathrm{n}=1083(11.7)\end{array}$ & $\begin{array}{l}\text { No } \\
\mathrm{n}=8155(88.3)\end{array}$ & P-Value & $\begin{array}{l}\text { Aspiration } \\
n=658(60.8)\end{array}$ & $\begin{array}{l}\text { Non-aspiration } \\
\mathrm{n}=425(39.2)\end{array}$ & P-Value \\
\hline Age, & & & & $<0.001$ & & & 0.759 \\
\hline 65 and below & $1404(15.2)$ & $51(4.7)$ & $1353(16.6)$ & & $29(4.4)$ & $22(5.2)$ & \\
\hline $66-75$ & $1868(20.2)$ & $158(14.6)$ & $1710(21.0)$ & & $97(14.7)$ & $61(14.4)$ & \\
\hline $76-85$ & $3481(37.7)$ & $451(41.6)$ & $3030(37.2)$ & & $268(40.7)$ & $183(43.1)$ & \\
\hline 86 and above & $2485(26.9)$ & $423(39.1)$ & $2062(25.3)$ & & $264(40.1)$ & $159(37.4)$ & \\
\hline Sex & & & & 0.402 & & & 0.882 \\
\hline Female & $4853(52.5)$ & $556(51.3)$ & $4297(52.7)$ & & $339(51.5)$ & $217(51.1)$ & \\
\hline Male & $4385(47.5)$ & $527(48.7)$ & $3858(47.3)$ & & $319(48.5)$ & $208(48.9)$ & \\
\hline OCSP Classification & & & & $<0.001$ & & & 0.759 \\
\hline LACS & $2134(23.1)$ & $113(10.4)$ & $2021(24.8)$ & & $57(8.7)$ & $56(13.2)$ & \\
\hline PACS & $3117(33.7)$ & $308(28.4)$ & $2809(34.4)$ & & $174(26.4)$ & $134(31.5)$ & \\
\hline POCS & $1581(17.1)$ & $142(13.1)$ & $1439(17.6)$ & & $88(13.4)$ & $54(12.7)$ & \\
\hline
\end{tabular}




\begin{tabular}{|c|c|c|c|c|c|c|c|}
\hline TACS & $1877(20.3)$ & $462(42.7)$ & $1415(17.4)$ & & $303(46.0)$ & $159(37.4)$ & \\
\hline Unspecified & $529(5.7)$ & $58(5.4)$ & $471(5.8)$ & & $36(5.5)$ & $22(5.2)$ & \\
\hline $\begin{array}{l}\text { Pre-Stroke Modified } \\
\text { Rankin Score }\end{array}$ & & & & $<0.001$ & & & 0.248 \\
\hline 0 & $5849(63.3)$ & $529(48.8)$ & $5320(65.2)$ & & $335(50.9)$ & $194(45.6)$ & \\
\hline 1 & $1100(11.9)$ & $149(13.8)$ & $951(11.7)$ & & $84(12.8)$ & $65(15.3)$ & \\
\hline 2 & $757(8.2)$ & $116(10.7)$ & $641(7.9)$ & & $64(9.7)$ & $52(12.2)$ & \\
\hline 3 & $883(9.6)$ & $154(14.2)$ & $729(8.9)$ & & $95(14.4)$ & $59(13.9)$ & \\
\hline 4 & $451(4.9)$ & $96(8.9)$ & $355(4.4)$ & & $53(8.1)$ & $43(10.1)$ & \\
\hline 5 & $198(2.1)$ & $39(19.7)$ & $159(1.9)$ & & $27(4.1)$ & $12(2.8)$ & \\
\hline Type of Stroke & & & & 0.939 & & & 0.065 \\
\hline Ischemic & $8037(87.0)$ & $943(87.1)$ & $7094(87.0)$ & & $563(85.6)$ & $380(89.4)$ & \\
\hline Hemorrhagic & $1201(13.0)$ & $140(12.9)$ & $1061(13.0)$ & & $95(14.4)$ & $45(10.6)$ & \\
\hline Admission Antithrombotic & & & & 0.073 & & & 0.633 \\
\hline Yes & $4745(51.4)$ & $584(53.9)$ & $4161(51.0)$ & & $307(46.7)$ & $192(45.2)$ & \\
\hline No & $4493(48.6)$ & $499(46.1)$ & $3994(49.0)$ & & $351(53.3)$ & $233(54.8)$ & \\
\hline
\end{tabular}




\begin{tabular}{|c|c|c|c|c|c|c|c|}
\hline Co-morbidities & & & & & & & \\
\hline Stroke/TIA & 1099 (11.9) & $147(13.6)$ & $952(11.7)$ & 0.070 & $84(12.8)$ & $63(14.8)$ & 0.334 \\
\hline $\mathrm{CHD} / \mathrm{MI}$ & $1625(17.6)$ & $265(24.5)$ & $1360(16.7)$ & $<0.001$ & $162(24.6)$ & $103(24.2)$ & 0.886 \\
\hline $\mathrm{AF}$ & $2239(24.2)$ & $400(36.9)$ & $1839(22.6)$ & $<0.001$ & $239(36.3)$ & $161(37.9)$ & 0.603 \\
\hline $\mathrm{CHF}$ & $996(10.8)$ & 199 (18.4) & $797(9.8)$ & $<0.001$ & $119(18.1)$ & $80(18.8)$ & 0.759 \\
\hline Hypertension & $4354(47.1)$ & $550(50.8)$ & $3804(46.6)$ & 0.010 & $334(50.8)$ & $216(50.8)$ & 0.984 \\
\hline Dyslipidemia & $863(9.3)$ & $72(6.6)$ & $791(9.7)$ & 0.001 & $44(6.7)$ & $28(6.6)$ & 0.949 \\
\hline Diabetes Mellitus & $1243(13.5)$ & $178(16.4)$ & $1065(13.1)$ & 0.002 & $108(16.4)$ & $70(16.5)$ & 0.980 \\
\hline PVD & $283(3.1)$ & $36(3.3)$ & $247(3.0)$ & 0.596 & $20(3.0)$ & $16(3.8)$ & 0.516 \\
\hline COPD & $541(5.9)$ & $101(9.3)$ & $440(5.4)$ & $<0.001$ & $52(7.9)$ & $49(11.5)$ & 0.045 \\
\hline Asthma & $664(7.2)$ & $87(8.0)$ & $577(7.1)$ & 0.252 & $51(7.8)$ & $36(8.5)$ & 0.670 \\
\hline History of pneumonia & $537(5.8)$ & $164(15.1)$ & $373(4.6)$ & $<0.001$ & $89(13.5)$ & $75(17.6)$ & 0.065 \\
\hline CKD & $380(4.1)$ & $62(5.7)$ & $318(3.9)$ & 0.004 & $25(3.8)$ & $37(8.7)$ & 0.001 \\
\hline Malignancy & $1112(12.0)$ & $155(14.3)$ & 957 (11.7) & 0.014 & $87(13.2)$ & $68(16.0)$ & 0.202 \\
\hline Dementia & $316(3.4)$ & $64(5.9)$ & $252(3.1)$ & $<0.001$ & $40(6.1)$ & $24(5.6)$ & 0.768 \\
\hline
\end{tabular}




\begin{tabular}{|l|l|l|l|l|l|l|l|l|}
\hline WCC, $x 10^{9} / \mathrm{L}$ & $9.1(4.4)^{*}$ & $10.30(5.5)^{*}$ & $9.00(4.2)^{*}$ & $<0.001$ & $10.10(5.6)^{* *}$ & $10.45(5.5)^{* *}$ & 0.281 \\
\hline CRP, mg/L & $12.00(33)^{*}$ & $26.00(60)^{*}$ & $11.00(28)^{*}$ & $<0.001$ & $23.00(55.0)^{* *}$ & $32.00(65.0)^{* *}$ & 0.010 \\
\hline
\end{tabular}

Categorical data are presented as frequency counts (\%) and continuous data such as WCC and CRP are presented as median (IQR).

* Subgroup analysis, $\mathrm{n}=7425$, a total of 1813 cases were not included in the analysis of WCC and CRP due to missing data.

**Subgroup analysis, $\mathrm{n}=1023$, a total of 60 cases were not included in the analysis due to missing WCC and CRP

Abbreviation: Oxfordshire Community Stroke Project (OCSP) classification, Lacunar stroke (LACS), Partial Anterior Circulation Stroke (PACS), Posterior Circulation Stroke (POCS), Total Anterior Circulation Stroke (TACS), Transient Ischemic Attack (TIA), Coronary Heart Disease (CHD)/ Myocardial Infarction (MI), Atrial Fibrillation (AF), Congestive Heart Failure (CHF), Peripheral Vascular Disease (PVD), Chronic Obstructive Pulmonary Disease (COPD), Chronic Kidney Disease (CKD. 
Table 2. Mortality of patients at different time periods

\begin{tabular}{|c|c|c|c|c|c|c|c|c|c|c|c|c|c|c|c|c|}
\hline \multirow{2}{*}{$\begin{array}{l}\text { Time } \\
\text { periods }\end{array}$} & \multicolumn{4}{|c|}{ No stroke-associated pneumonia } & \multicolumn{4}{|c|}{ Stroke-associated pneumonia } & \multicolumn{4}{|c|}{ Aspiration pneumonia } & \multicolumn{4}{|c|}{ Non-aspiration pneumonia } \\
\hline & $\begin{array}{l}\text { No. } \\
\text { at } \\
\text { risk }\end{array}$ & $\begin{array}{l}\text { No. } \\
\text { deaths } \\
(\%)\end{array}$ & $\begin{array}{l}\text { Risk of } \\
\text { mortality } \\
\text { (chance in } \\
1000 \text { )/wk }\end{array}$ & $\begin{array}{l}\text { Cumulative } \\
\text { mortality } \\
\text { function(\% } \\
(95 \% \mathrm{CI})\end{array}$ & $\begin{array}{l}\text { No. } \\
\text { at } \\
\text { risk }\end{array}$ & $\begin{array}{l}\text { No. } \\
\text { deaths } \\
(\%)\end{array}$ & $\begin{array}{l}\text { Risk of } \\
\text { mortality } \\
\text { (chance } \\
\text { in 1000)/ } \\
\text { wk }\end{array}$ & $\begin{array}{l}\text { Cumulative } \\
\text { mortality } \\
\text { function }(\%) \\
(95 \% \mathrm{CI})\end{array}$ & $\begin{array}{l}\text { No. } \\
\text { at } \\
\text { risk }\end{array}$ & $\begin{array}{l}\text { No. } \\
\text { deaths } \\
(\%)\end{array}$ & $\begin{array}{l}\text { Risk of } \\
\text { mortality } \\
\text { (chance } \\
\text { in 1000)/ } \\
\text { wk }\end{array}$ & $\begin{array}{l}\text { Cumulative } \\
\text { mortality } \\
\text { function(\%) } \\
(95 \% \mathrm{CI})\end{array}$ & $\begin{array}{l}\text { No. } \\
\text { at } \\
\text { risk }\end{array}$ & $\begin{array}{l}\text { No. } \\
\text { deaths } \\
(\%)\end{array}$ & $\begin{array}{l}\text { Risk of } \\
\text { mortality } \\
\text { (chance } \\
\text { in 1000)/ } \\
\text { wk }\end{array}$ & $\begin{array}{l}\text { Cumulative } \\
\text { mortality } \\
\text { function(\%) } \\
(95 \% \mathrm{CI})\end{array}$ \\
\hline In-patient & 8155 & $\begin{array}{l}1305 \\
(16.0)\end{array}$ & - & $\begin{array}{l}16.0 \\
(15.3-16.8)\end{array}$ & 1083 & $\begin{array}{l}666 \\
(61.5)\end{array}$ & - & $\begin{array}{l}61.5 \\
(58.6-64.4)\end{array}$ & 658 & $\begin{array}{l}433 \\
(65.8)\end{array}$ & - & $\begin{array}{l}65.8 \\
(62.2-69.4)\end{array}$ & 425 & $\begin{array}{l}233 \\
(54.8)\end{array}$ & - & $\begin{array}{l}54.8 \\
(62.2-69.4)\end{array}$ \\
\hline 0-90 Days & 8155 & $\begin{array}{l}1761 \\
(21.6)\end{array}$ & 16.6 & $\begin{array}{l}1.6 \\
(20.7-22.5)\end{array}$ & 1083 & $\begin{array}{l}714 \\
(65.9)\end{array}$ & 50.7 & $\begin{array}{l}65.9 \\
(63.1-68.7)\end{array}$ & 658 & $\begin{array}{l}458 \\
(69.6)\end{array}$ & 53.5 & $\begin{array}{l}69.6 \\
(66.1-73.1)\end{array}$ & 425 & $\begin{array}{l}256 \\
(60.2)\end{array}$ & 46.3 & $\begin{array}{l}60.2 \\
(55.6-64.9)\end{array}$ \\
\hline $\begin{array}{l}91-365 \\
\text { Days }\end{array}$ & 6394 & $\begin{array}{l}678 \\
(10.6)\end{array}$ & 2.7 & $\begin{array}{l}29.9 \\
(28.9-30.9)\end{array}$ & 369 & $\begin{array}{l}83 \\
(22.5)\end{array}$ & 5.7 & $\begin{array}{l}73.6 \\
(71.0-76.2)\end{array}$ & 200 & $\begin{array}{l}49 \\
(24.5)\end{array}$ & 6.2 & $\begin{array}{l}77.1 \\
(73.9-80.3)\end{array}$ & 169 & $\begin{array}{l}34 \\
(20.1)\end{array}$ & 5.1 & $\begin{array}{l}68.2 \\
(63.8-72.6)\end{array}$ \\
\hline $\begin{array}{l}366-1095 \\
\text { Days }\end{array}$ & 5716 & $\begin{array}{l}723 \\
(12.6)\end{array}$ & 1.2 & $\begin{array}{l}38.8 \\
(37.7-39.9)\end{array}$ & 286 & $\begin{array}{l}56 \\
(19.6)\end{array}$ & 1.9 & $\begin{array}{l}78.8 \\
(76.4-81.2)\end{array}$ & 151 & $\begin{array}{l}28 \\
(18.5)\end{array}$ & 1.8 & $\begin{array}{l}81.3 \\
(78.3-84.3)\end{array}$ & 135 & $\begin{array}{l}28 \\
(20.7)\end{array}$ & 2.0 & $\begin{array}{l}74.8 \\
(70.7-78.9)\end{array}$ \\
\hline $\begin{array}{l}1096- \\
3650 \\
\text { Days }\end{array}$ & 4993 & $\begin{array}{l}775 \\
(15.5)\end{array}$ & 0.4 & $\begin{array}{l}48.3 \\
(47.2-49.4)\end{array}$ & 230 & $\begin{array}{l}22 \\
(9.6)\end{array}$ & 0.3 & $\begin{array}{l}80.8 \\
(78.5-83.2)\end{array}$ & 123 & $\begin{array}{l}12 \\
(9.8)\end{array}$ & 0.3 & $\begin{array}{l}83.1 \\
(80.2-86.0)\end{array}$ & 107 & $\begin{array}{l}10 \\
(9.3)\end{array}$ & 0.3 & $\begin{array}{l}77.2 \\
(73.2-81.2)\end{array}$ \\
\hline
\end{tabular}


Table 3. Odds /Hazards ratio with corresponding 95\% confidence intervals at different time periods for mortality outcomes and long length of hospital stay for patients with SAP compared to those without that were admitted to the regional stroke unit (2003 to 2015) in Norfolk, England, UK.

\begin{tabular}{|c|c|c|c|c|c|c|}
\hline Model & \multicolumn{5}{|l|}{ Mortality $\dagger$} & $\begin{array}{l}\text { Odds of Long Length of } \\
\text { Stay }(>14 \text { days }) \dagger\end{array}$ \\
\hline A & $8.38(7.32-9.60) * * *$ & $4.08(3.73-4.45) * * *$ & $2.28(1.81-2.86) * * *$ & $1.63(1.24-2.14) * * *$ & $0.62(0.41-0.95)^{*}$ & $2.76(2.43-3.14) * * *$ \\
\hline B & $7.60(6.60-8.74) * * *$ & $3.50(3.21-3.83) * * *$ & $1.91(1.52-2.40) * * *$ & $1.38(1.05-1.82)^{*}$ & $0.54(0.35-0.82)^{* *}$ & $2.48(2.17-2.82) * * *$ \\
\hline $\mathrm{D}$ & $6.75(5.75-7.92) * * *$ & $2.36(2.15-2.60) * * *$ & $1.58(1.25-2.00) * * *$ & $1.34(1.01-1.76) *$ & $0.58(0.37-0.88)^{*}$ & $2.23(1.94-2.55) * * *$ \\
\hline $\mathrm{E}$ & $6.56(5.58-7.70) * * *$ & $2.29(2.09-2.52) * * *$ & $1.51(1.19-1.92) * *$ & $1.21(0.92-1.60)$ & $0.59(0.38-0.91)^{*}$ & $2.17(1.89-2.48) * * *$ \\
\hline $\mathrm{F}$ & $5.87(4.97-6.93) * * *$ & $2.17(1.97-2.40) * * *$ & $1.31(1.03-1.67) *$ & $1.11(0.83-1.47)$ & $0.50(0.32-0.78)^{* *}$ & $1.93(1.67-2.22) * * *$ \\
\hline
\end{tabular}

P-value $*<0.05, * *<0.01, * * *<0.001$

Model A= Unadjusted

Model $\mathrm{B}=$ Adjusted for age and sex

Model C= Adjusted for model B + stroke type, Oxfordshire Community Stroke Project Classification, and prior antiplatelet use

Model D= Adjusted for model C + and co-morbidities $\dagger \dagger$ 
Model E= Adjusted for model E + pre-stroke modified Rankin score

Model F= Adjusted for model E + WCC and CRP. Subgroup analysis, $\mathrm{n}=7425$

$\dagger$ The in-patient mortality and odds of long length of stay are derived from binary logistic regression models. The 90-, 365- and 1095-days mortality hazard ratios are analyzed by Cox regression models. Long length of stay is defined as hospital stay of more than 14 days since the day of admission.

$\dagger$ Co-morbidities adjusted include Previous Stroke/TIA, MI/CHD, AF, CHF, Hypertension, Hyperlipidemia, Diabetes Mellitus, Peripheral Vascular Disease, COPD, Asthma, Pneumonia before admission, CKD, Malignancy, Dementia 


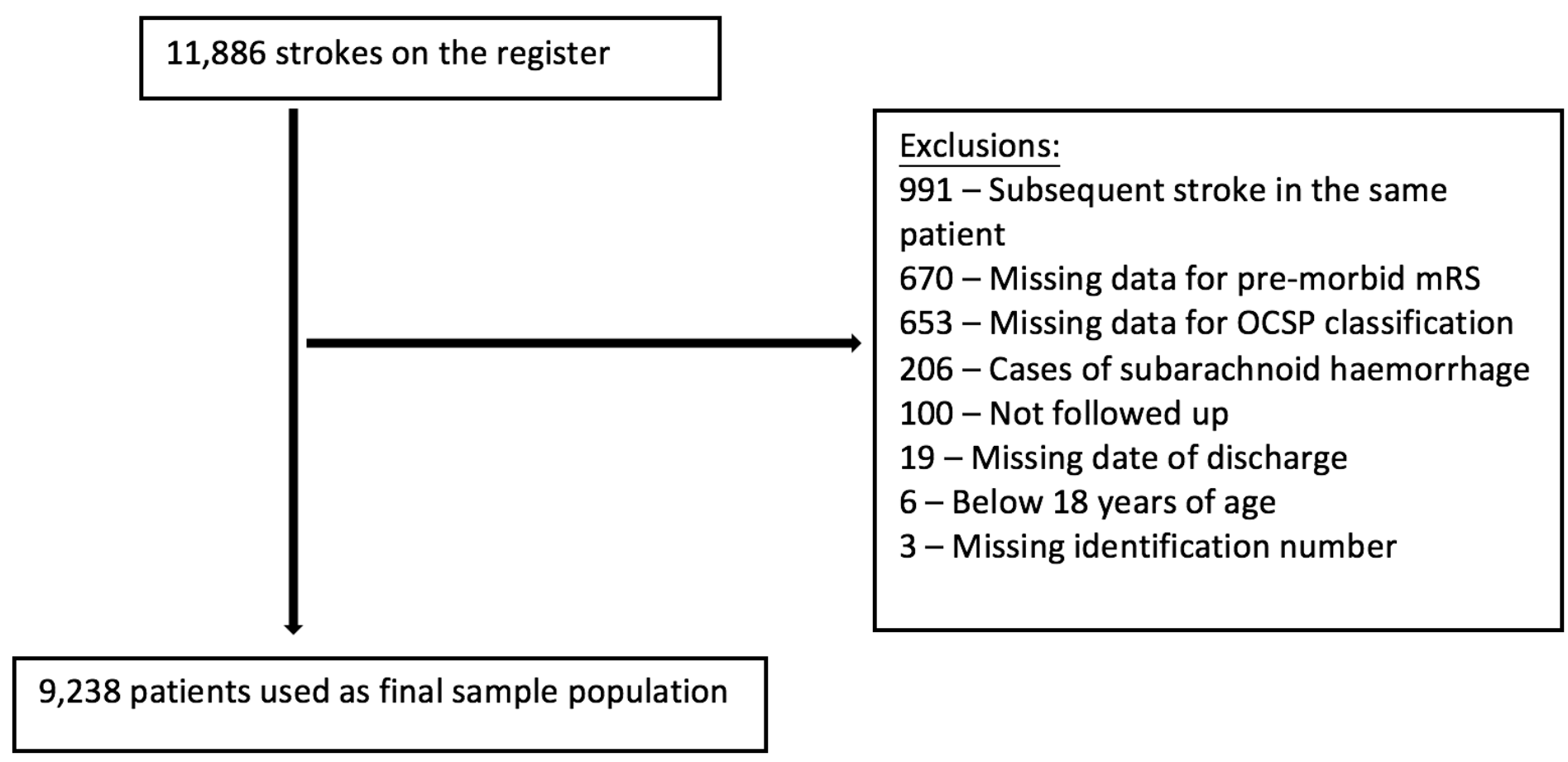


Supplementary Figure a-2: Survival following diagnosis of stroke according to pneumonia status (Kaplan-Meier survival curve), $\mathrm{n}=9238$; Log rank test, $\mathrm{p}<0.001$.

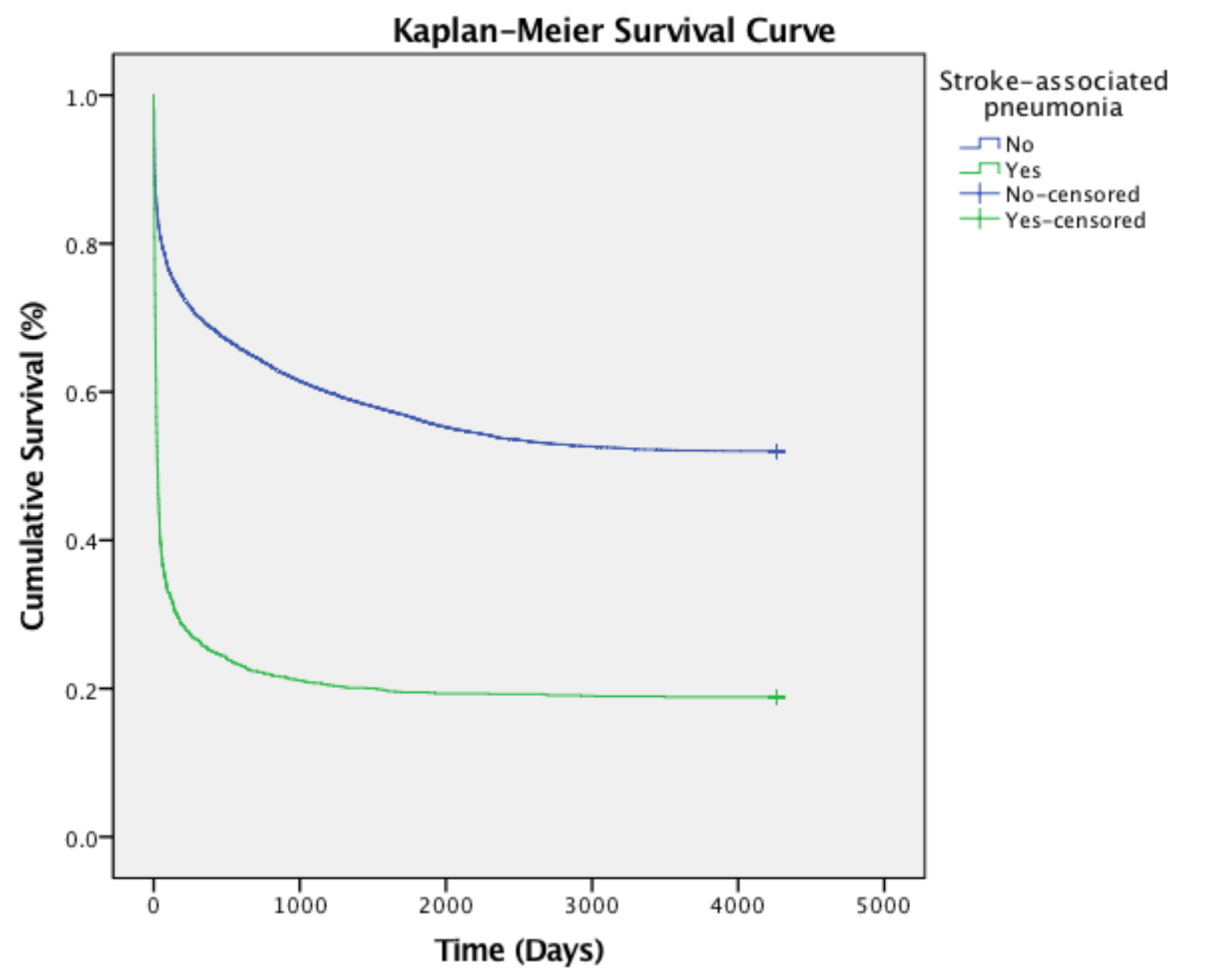


Supplementary Figure a-3: Survival following diagnosis of stroke according to subtypes of stroke-associated pneumonia; either aspiration or non-aspiration pneumonia (Kaplan-Meier survival Curve), $n=1083$; Log rank test, $\mathrm{p}<0.001$.

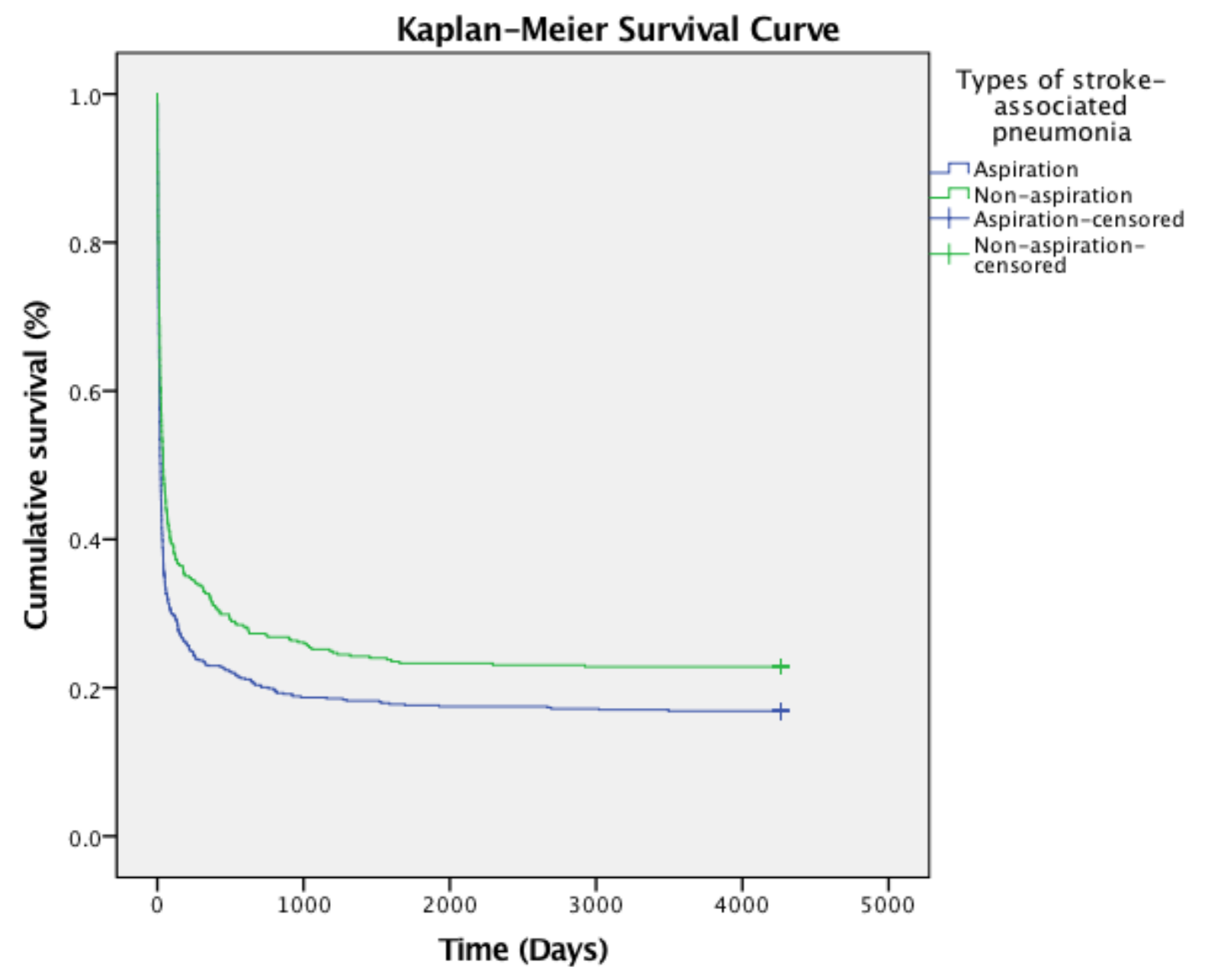


Supplementary Figure a-4: Risk estimates of outcome for aspiration pneumonia vs non-aspiration pneumonia (with non-aspiration pneumonia as the reference category)

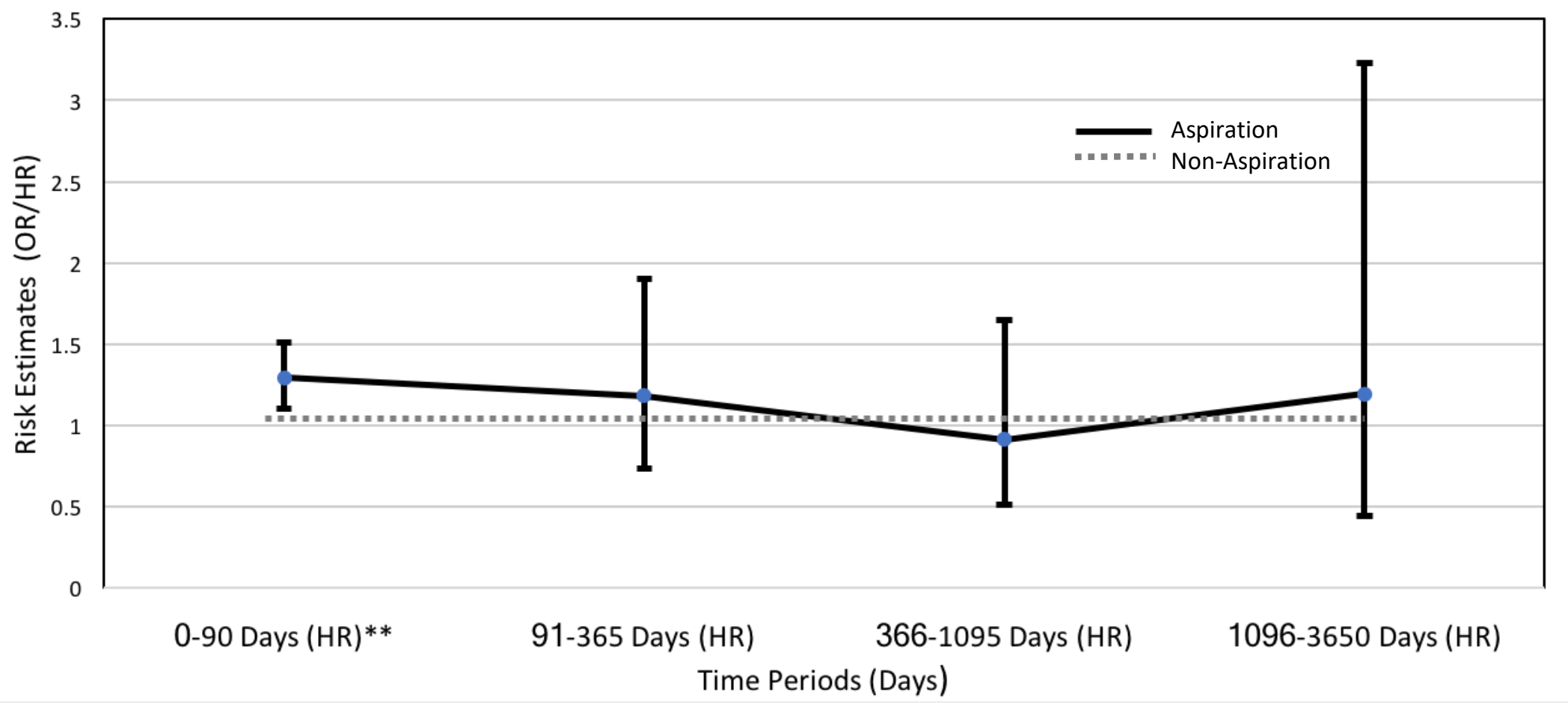

$\mathrm{P}^{*}<0.05, * *<0.01, * * *<0.001$

Binary logistic models were used in the analysis of in-patient mortality and long length of stay. Cox-regression models were used to analyze the 90-, 365-, 1095- and 3650- Days mortality.

All Binary Logistic Models and Cox-regression Models were Adjusted For: Age, Sex, Stroke Type, Oxfordshire Community Stroke Project Classification, Pre-stroke modified Rankin score, Prior Antiplatelet Use, Co-Morbidities (Previous Stroke/Transient Ischemic Attack,

Myocardial Infarction/Coronary Heart Disease, Congestive Heart Failure, Hypertension, Hyperlipidemia, Diabetes Mellitus, Peripheral Vascular Disease, Chronic Obstructive Pulmonary Disease, Chronic Kidney Disease, Falls, Malignancy, Dementia) 
Supplementary Figure a-5: Functional outcome at discharge of all stroke patients ( $=6013)$ and those of the subgroups stratified according to pneumonia status ( SAP vs non-SAP) and pneumonia type (aspiration vs non-aspiration)

\section{Modified rankin score}

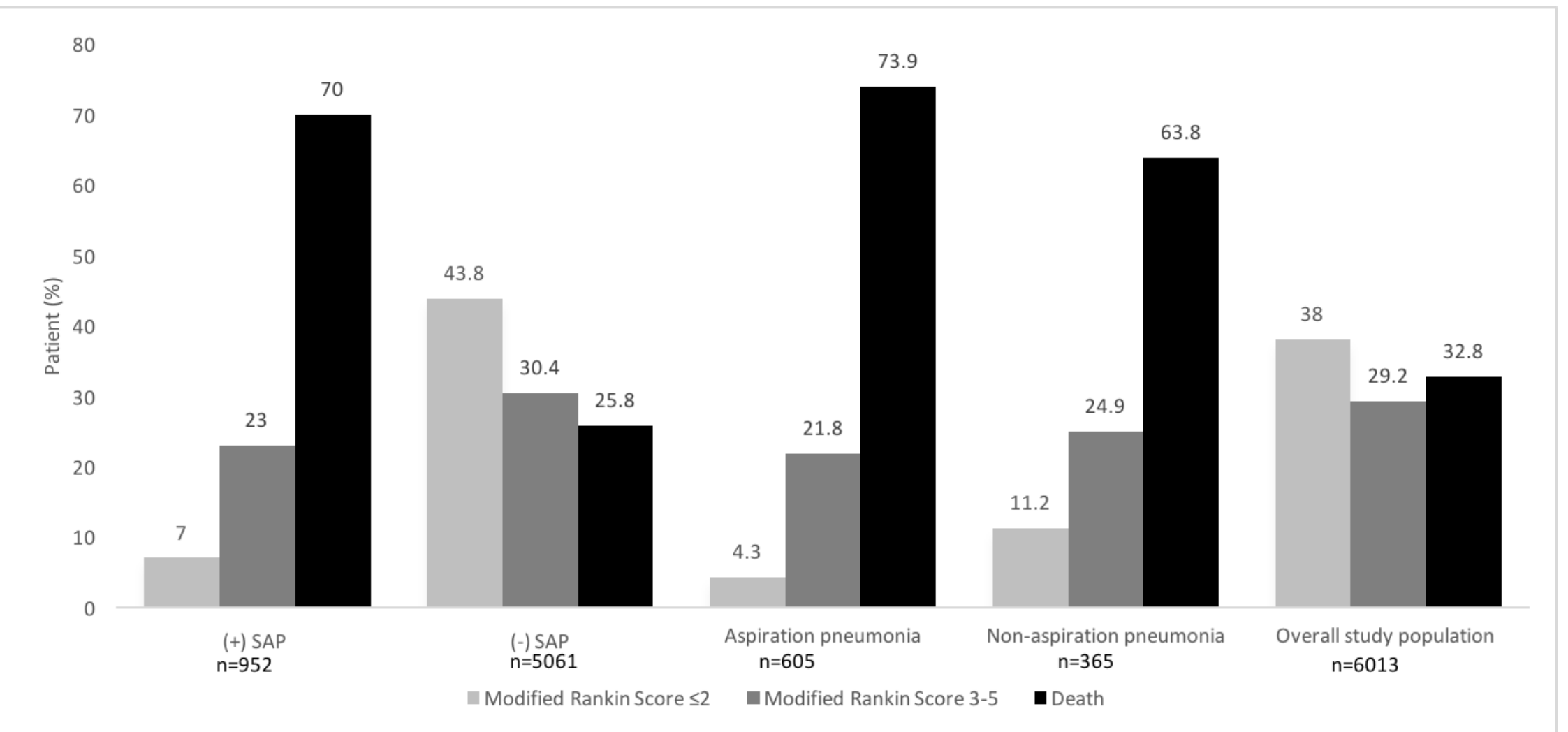

Functional outcomes at discharge were available in $65 \%$ of patients. Binary logistic regression analysis was performed in $65 \%$ (n=6013) patients who had available discharge $\mathrm{mRS}$ and $\mathrm{p}$ value was obtained. SAP was associated with a poor outcome at discharge, OR 7.17 (95\%CI 5.44-9.45), $\mathrm{p}<0.001$. Good outcome was defined as mRS 0-2 and poor outcome was defined as 3-6. 
